\title{
Marie Curie - „Elemente des Lebens“
}

Ferien unter Einhaltung aller Corona-Auflagen - statt zu vereisen, gehen Sie ins Kino.

Marie Curie, in der Regie von Marjane Satrapi, bietet eine fachliche Zeitreise zur vorletzten Jahrhundertwende und verbindet Wissenschaftsgeschichte mit Weltgeschichte.

Die Entdeckungen und Forschungen der polnischen Chemikerin und Physikerin Marie Curie (1867-1934) in Frankreich haben bis heute unweigerliche Auswirkungen auf den Alltag der Menschen und den Berufsalltag von Radiologinnen. Die visio- näre Pionierin hatte zeit ihres Lebens mit Widerständen in der männlich dominierten Wissenschaftswelt zu kämpfen. Sie entdeckte die chemischen Elemente Polonium und Radium und die Radioaktivität. Sie wurde mit zwei Nobelpreisen (Physik und Chemie) ausgezeichnet und wurde dazwischen die erste Professorin an der Universität Sorbonne in ihrer Wahlheimatstadt Paris. Ihre polnische Herkunft machte sie zudem zur Zielscheibe der französischen Presse. Eine wichtige Stütze fand sie nur in ihrem Forschungspartner und späterem Ehemann Pierre. Neben dem Sexismus ihrer
Zeit kämpft Curie dabei auch mit dem Wissen darum, was ihre Entdeckung von Polonium und Radium für die Zukunft der Menschheit bedeuten könnte - neben Fortschritt lauert in der von ihr selbst so benannten Radioaktivität auch Gefahr, da auch ihre Gesundheit bereits angeschlagen war.

Spannend erzählt, stellenweise ein bisschen melodramatisch - eine schöne Zeitreise für knapp zwei Stunden. 